\title{
O Ensino Superior: as antígonas de nosso tempo pandêmico e o agravo das desigualdades sociais
}

\begin{abstract}
Resumo: A pandemia que vivemos escancarou e, ao mesmo tempo, provocou um agravo nas desigualdades sociais históricas do Brasil. Essa condição é consequência de processos de colonização que são vividos até hoje, pois não conseguimos enfrentar o racismo, a violência de gênero, a exploração do trabalho e outras mazelas sociais. Todas estas questões, em um tempo de profunda fragilidade sanitária, nos mostram que os que mais sofrem continuam sendo os mais pobres. A COVID-19 nos apresenta a face mais violenta desta desigualdade. O campo da educação também é afetado por este cenário, e neste texto discutimos o caso da educação superior em um uma universidade pública, para problematizar a permanência de processos de exclusão. Com a suspensão das aulas, busca-se compensar o ensino presencial através de propostas de atividades remotas (ERE). A implementação da proposta poderá aprofundar as desigualdades, dadas as condições precárias com que está se dando essa discussão, na qual aparecem invisibilizadas as dificuldades daquele público que tem sido trazido para a universidade nos últimos anos através de políticas afirmativas.
\end{abstract}

Palavras-Chave: Colonização. Pandemia. Ensino Remoto Emergencial. Desigualdades socioeducacionais.

\section{Introdução}

Por que demoras, pois? Em tuas palavras tudo me causa horror,

E assim seja sempre! Também todos os meus atos te serão Odiosos! Que maior glória posso eu te pretender, do que a de repousar no tumulo de meu irmão? Estes homens (indica o coro) confessariam que aprovam o que fiz se o terror não thes tolhesse a lingua. Mas, um dos privilégios da tirania consiste em dizer, e fazer, o que quiser

(Antígona)

A Pandemia causada pela COVID-19 nos apresenta um terrível cenário, cuja mais grave expressão se encontra no número crescente de óbitos no Brasil e na triste imagem de não podermos enterrar nossos mortos. Cenas que aparecem todos os dias na mídia, mostram a luta de familiares para saberem notícias sobre seus parentes nos hospitais públicos lotados e muitos, lamentavelmente, buscam forças para lidar com impossibilidade de sequer ver o corpo de quem, devido à corona vírus, não pode ser mostrado. Familiares impedidos de enterrar seus entes queridos, feito Antígona, ${ }^{1}$ lutam por um último adeus, pela garantia de uma mínima dignidade na hora da partida. Essa triste imagem mostra ainda mais a importância das instituições públicas como o Sistema Único de Saúde (SUS),
Magali Mendes de Menezes Universidade Federal do Rio Grande do Sul - UFRGS magaliufrgs@gmail.com Pedro de Almeida Costa Universidade Federal do Rio Grande do Sul - UFRGS pedrodealmeidacosta@gmail.com

(1) Antígona é uma peça teatral greg̣a, continuação dramática de Édipo Rei de Sófocles. No enredo, a personagem Antígona é impedida de enterrar seu irmão, por ordem do soberano Sua atitude pode representar a contrariedade e rebeldia do sujeito ante a arbitrariedade do Estado, simbolizada na vedação do direito até mesmo ao luto. 
que traz o trabalho incansável de médicos, enfermeiros, auxiliares de enfermagem e todos envolvidos no cuidado a saúde; e das universidades que não pararam, realizando pesquisas na busca de respostas às demandas sociais, ao que é urgente neste momento. Percebemos mais do que nunca, a importância do que é público e a necessidade incondicional de sua defesa. Contudo, esse cenário também nos mostrou o quanto as desigualdades sociais se agravaram, pois é inegável que a pandemia atingiu mais aqueles que estão em situação de vulnerabilidade social. Os espaços racialmente identificados como pretos, o caso das favelas, de conjuntos habitacionais, de bairros que vivem situações de precariedade sanitária sem as mínimas condições de vida, são espaços mais atingidos pela pandemia. Enquanto que uma pequena parcela da população pode se resguardar e estar em distanciamento social outra, vai à luta, buscando ironicamente sobreviver, quando justamente este ato pode levar muitos ao óbito. A pandemia traz o que a própria Organização das Nações Unidas (ONU) chamou de uma "discriminação endêmica". Segundo dados de uma pesquisa realizada pela Pontifícia Universidade Católica do Rio de Janeiro (PUC-Rio) "[...] pretos e pardos apresentaram maior percentagem de óbitos em relação aos brancos, em todos os níveis de escolaridade [...], uma proporção 4 vezes maior de morte do que brancos com nível superior (80,35\% contra 19,65)". (REUTERS, 2020)

Não há dúvida de que a pandemia nos exige uma leitura interseccional, permeada por questões de classe, raça e gênero. Este momento coloca em relevo questões que não surgiram agora, mas que se agravam dentro de um contexto de total descaso com a vida. Não conseguimos enfrentar o racismo institucional muito menos o machismo, que compõe nossas relações e instituições (neste período constatou-se aumento significativo do feminicídio no Brasil). Quando estas questões não são enfrentadas, ao contrário, muitas vezes são negadas com a falácia de ainda vigente de que vivemos em uma democracia racial, estas questões retornam de uma forma muito mais intensa.

Negação (denial em inglês, no sentido de recusa) é um mecanismo de defesa do ego que opera de forma inconsciente para resolver conflitos emocionais através da recusa em admitir os aspectos mais desagradáveis da realidade externa, bem como sentimentos e pensamentos internos. (KILOMBA, 2019, p. 43) 
Grada Kilomba analisa a negação como um mecanismo fundamental na produção da branquitude, de um sujeito branco que ao produzir-se produz também a imagem do Outro. Nessa direção a autora continua, "[...] não é com o sujeito negro que estamos 1idando, mas com fantasias brancas sobre o que a negritude deveria ser". (KILOMBA, 2019, p. 38)

Como que estas questões afetam a educação no Brasil? De que maneira o caos político, sanitário, ético, de uma barbárie legitimada, tem afetado nossas escolas, nossas universidades? Tivemos a suspensão das aulas, contudo tem-se buscado alternativas para garantir a continuidade do calendário escolar. O ensino remoto surge como uma destas alternativas. Mas será que o ensino remoto não poderá tornar-se um campo de agravo destas desigualdades? Em outras palavras, como a como impedir que a Educação, mais do que nos ajudar a enterrar nossos mortos, possa ser um espaço de vida como expressão máxima da justiça social?

\section{Modernidade-colonialidade: as raízes da desigualdade}

A educação não é sinônimo de escola. Mas a escola, a partir do que os pensadores/as decoloniais chamam modernidade-colonialidade, torna-se a instituição por excelência, legitimadora do conhecimento. O termo modernidade/colonialidade foi cunhado dentro do pensamento decolonial em que a modernidade europeia não pode ser compreendida sem o processo de colonização. Pensadores como Walter Mignolo, Aníbal Quijano, Ramón Grasfoguel, Nelson Maldonado Torres, Enrique Dussel, Catherine Walsh, Zulma Palermo, entre outros, são referências do pensamento decolonial.

Para esses pensadores não é possível compreender a modernidade sem admitirmos o quanto o processo de colonização foi fundamental para a constituição do que chamamos Modernidade. A Modernidade (um projeto ainda inacabado) como um acontecimento imposto a toda humanidade fez com que o processo de colonização se tornasse fundamental para a afirmação deste momento histórico. A Modernidade compreendida como movimento de ocidentalização do mundo carrega em si um projeto econômico, social, político, estético, epistemológico ancorado em uma nova percepção de humanidade. Contudo, os "modernos" deveriam explicar como um projeto que trazia em seu núcleo a defesa da "igualdade, liberdade e fraternidade" (das três ideias defendidas, a última bandeira é a 
que menos se fala até hoje) pode colonizar outros povos, dizimando a muitos, escravizando outros, anulando culturas e vidas num movimento de integracionismo ou morte! Quijano (2005) comenta que a ideia de raça foi essencial nesta explicação, pois criou as condições necessárias para justificar a exploração e negação de parte da humanidade. O racismo tornou-se assim, potente instrumento de controle da população trabalhadora. A colonização fez com que se imprimissem classificações de humanidade. Essa ideia não era nova, pois se formos pensar desde os gregos, era enfatizado que os humanos possuíam naturezas diferentes. Em Platão (2002), temos a explicação de que alguns nascem para serem escravos, outros para governar, ou seja, a desigualdade se justifica pelas naturezas humanas diferenciadas, uns são naturalmente superiores a outros. Na Modernidade a diferença se impôs de outras formas, apoiada no discurso da própria ciência, menina dos olhos da modernidade e sustentadora do ideal de verdade, o racismo passou a ser justificado. Como comenta Quijano (2005, p. 117), "[...] a codificação das diferenças entre conquistadores e conquistados na ideia de raça, ou seja, uma supostamente distinta estrutura biológica que situava a uns em situação natural de inferioridade em relação a outros." A América Latina vista como o "não ser", expressão cunhada por Zimmerman (1987) carrega a dura tarefa de afirmar sua humanidade. Negros e indígenas, desde o processo de colonização, não são vistos como humanos, pois a humanidade como uma categoria moderna, universalizou a visão de humanidade, o europeu é o humano por excelência e todos/as àqueles/as que não estivessem de acordo com esta visão eram excluídos da humanidade. Na mesma direção, Zea (2005, p. 358) nos diz que a filosofia latino-americana "[...] começa assim, com uma polêmica sobre a essência do humano e a relação que pudesse ter esta essência com os raros habitantes do continente descoberto, conquistado, colonizado". Enquanto, a filosofia para os gregos inicia com a capacidade de admiração, para nós latino-americanos, a filosofia começa na defesa de nossa humanidade. A colonialidade é, portanto, um processo de colonização até hoje existente, que assume diferentes dimensões e encontra na Educação, com certeza, um terreno estratégico para sua continuidade. A educação escolar, é um dos mecanismos mais importantes para efetivação da modernidade/colonialidade, pois, conseguiu reunir em si mesma as três dimensões da colonialidade: do poder, saber e ser. Como comenta Boaventura (2010, p. 39) 
"A negação de uma parte da humanidade é sacrificial, na medida em que constitui a condição para outra parte da humanidade se afirmar enquanto universal".

A escola e a "grande escola" que muitas vezes é a Universidade, representa este espaço de disputa, reproduz, cria e recria em si mesma, mecanismos de manutenção da ordem estabelecida, da produção de sujeitos. É um espaço de contradições ao mesmo tempo é estratégica na manutenção deste projeto colonizador, produz re-existências. Que Antígonas então o nosso tempo pandêmico é capaz de produzir? E aqui cabe lembrar que Antígona desafiou o poder do Estado, contra uma ordem estabelecida. Para aprofundar estas indagações nos deteremos a analisar o espaço acadêmico.

\section{O Ensino Superior: a luta pelas ações afirmativas}

A democratização do acesso à universidade pública no Brasil é uma conquista recente e inacabada. Como assinalava Fernandes (1975), o modelo de escola superior trazido pela coroa Portuguesa para a colônia - e que seria embrião do que hoje são nossas universidades - não cumpriu papel de modernização da vida social e não ativou dinâmicas que pudessem renovar as estruturas coloniais. O resultado foi uma instituição conservadora e elitista, com função limitada de formação de bacharéis e letrados para alimentar a incipiente burocracia e criar algum grau de distinção social aos diplomados.

No formato atual, nossas universidades são tardias em relação a outras fundadas no continente latino-americano. Também seu alcance, em relação à população em idade de estudar esse grau, mostra um sistema aquém de qualquer comparação com outros países (AMARAL, 2016), mesmo com as expansões havidas durante os governos da ditadura cívico-militar (1964-1985) e nos governos do Partido do Trabalhador (PT) (2003-2016).

É muito recente a reserva de vagas para segmentos sociais marcados por vulnerabilidades econômicas e/ou raciais, e que, historicamente, enfrentam dificuldades para acessar a universidade através dos processos seletivos tradicionais. Essa conquista não foi uma dádiva ou concessão da instituição universidade, mas resultado de longas e duras lutas dos movimentos sociais que dão voz aos recortes populacionais mais frágeis, como negros, pobres e indígenas. O caso particular da Universidade Federal do 

somente em 08 junho de 2017 o Supremo Tribunal Federal profere acórdão que assegura a sua constitucionalidade e impede que novas contestações sejam feitas.
Rio Grande do Sul (UFRGS), por exemplo, foi marcado por uma luta muito grande do movimento negro, que demandava acesso a universidade à uma comissão interna da universidade composta exclusivamente por pessoas brancas, como lembra Anjos (2012).

Em 2012, foi publicada a Lei $n^{\circ} 12.71129$ agosto de 2012, que oficializa a chamada reserva de vagas nas universidades e institutos federais, para alunos egressos de escolas públicas. ${ }^{2}$ Dentro dessa reserva, a metade das vagas são para pessoas com determinado corte de renda per capita familiar. Nesses dois grupos recortados pelo critério de renda, há a reserva para pessoas autodeclaradas pretas, pardas ou indígenas e, a partir de 2016, também para pessoas com deficiências. A Lei previa implantação gradual de reservas até atingir o patamar de 50\%, em 2016. Entretanto, várias universidades públicas federais e estaduais já tinham reservas de vagas para grupos de determinadas características socioeconômicas e/ ou raciais quando a Lei foi promulgada. A pioneira no Brasil foi a Universidade Estadual do Rio de Janeiro (UERJ) em 2002, mas nos dez anos que separam essa prática pioneira da promulgação da Lei em 2012, 32 universidades federais já tinham alguma forma de reserva de vagas.

Tal política implicou em mudanças profundas no perfil discente das universidades públicas federais. Realizada em cinco edições, desde 1996, a Pesquisa do perfil socioeconômico e cultural dos estudantes de graduação feitas pelo Fórum de Pró-Reitores de assuntos comunitários e estudantis (FONAPRACE) da Associação Nacional de Dirigentes de Instituições de Ensino Superior (ANDIFES, 2018),tem mostrado os números dessa transformação. Atualmente, 54,6\% dos estudantes são mulheres; 51,2\% são autodeclarados pretos ou pardos (em 2003 eram pouco mais de 32\%); dois terços frequentaram o Ensino Médio em escolas públicas (eram 37,5\% em 2003); o mesmo contingente são de famílias em que nem pai nem mãe possuem curso superior; e 70,2\% das famílias dos estudantes possuem renda per capita inferior a 1,5 salário mínimo (em 1996 esse percentual era de 43\%).

Para dar conta desses novos cidadãos e cidadãs que passaram a frequentar as universidades públicas, é instituído em 2010, pelo Decreto $n^{0} 7.234 / 2010$, um programa específico para financiar a chamada assistência estudantil (Programa Nacional de Assistência Estudantil - PNAES). Sua condição de vulnerabilidade demanda políticas de permanência que garantam condições de estudo, como 
bolsas, subsídio para alimentação, moradia estudantil, assistência médica e odontológica, entre outros. O financiamento dessa política também cresceu, (MINISTÉRIO DA EDUCAÇÃO, 2012) contudo, como aponta Barbosa e Silva (2017), o número de estudantes em situação de vulnerabilidade social e dependentes das políticas de assistência cresceu mais, de modo que a capacidade de investimento per capita das universidades públicas foi decrescendo à medida que o programa ia sendo implementado.

Além da redução de recursos específicos para o segmento mais vulnerável dos estudantes, as Instituições Federais de Ensino Superior (IFES) enfrentam um orçamento decrescente desde 2015, em valores atualizados (CENTRO DE ESTUDOS E DEBATES ESTRATÉGICOS DA CÂMARA DOS DEPUTADOS, 2018), somado aos efeitos da Emenda Constitucional no 95/2016, que inviabiliza o atingimento das metas de expansão previstas no Plano Nacional de Educação, segundo estudo de Amaral (2018).

\section{A inclusão/exclusão de nossos estudantes}

É nesse quadro de inacabada e imperfeita expansão e democratização da educação superior, que a universidade pública brasileira recebe a pandemia da COVID-2019. De forma responsável e prudente, as universidades cessam em março de 2020 todas as atividades presenciais administrativas e acadêmicas, ao mesmo tempo que mantém atividades essenciais e se debruça de forma incansável sobre pesquisas e outras ações de combate e mitigação dos efeitos da pandemia. ${ }^{3}$

Especialmente no Brasil, a necessidade de afastamento social se alonga e aprofunda devido à ausência de coordenação técnica e política do governo federal, que adotou desde o início postura negacionista, disseminou proposta de tratamento com medicamento testado de forma inconclusiva, que trocou duas vezes o titular do Ministério da Saúde que não se submetiam a esse desmando e que, até o fechamento desse texto, permanecia sob a gestão de um general do exército sem experiência em gestão de saúde. Resultado é um número absurdo de mortes e contaminações, possivelmente subnotificadas, e o prognóstico de que as medidas de isolamento e distanciamento social ainda deverão perdurar por muito tempo.

A par da crise sanitária, também o Ministério da Educação (MEC) segue pressionando as universidades federais a retomarem atividades ${ }^{4}$ reedita o programa Future-se - já rechaçado por quase a
(3) Em 11 maio de 2020 a ANDIFES publica resultado de levantamento com as 67 IFES (45 respostas) e aponta 823 pesquisas em andamento com a finalidade de mapear, conhecer especificidades do novo coronavirus e encontras a vacina contra a COVID-19, além da existência, nos hospitais universitários, de 2.228 leitos normais destinados para tratamento da COVID-19 e de 489 leitos de UTI. Destacaram-se também, 96 ações envolvendo produção de álcool em gel e álcool líquido, com quase um milhão de litros já produzidos no formato de gel e 912.000 litros no estado líquido. A confecção de Equipamentos de Proteção Individual - EPI também alcançou índices notáveis, com a produção, até o momento, de 162.964 protetores faciais, 85.514 máscaras de pano, 20.200 unidades diversas 6.000 aventais e 2.000 capuzes. (UNIVERSIDA FEDERAL DO ESPÍRITO SANTO, 2020)

(4) Ver, por exemplo, a ideia de premiar com recursos financeiros as IFES que não suspenderem atividades na pandemia (Ver: TURTELLI, 2020) e, também, a edição da Instrução Normativa 28/2020 que proíbe pagamento de adicionais e vantagens a servidores que não estejam trabalhando presencialmente. 
totalidade das universidades federais em 2019 - como projeto de Lei (PL n ${ }^{\circ}$ 3076/2020 em 02/06/2020), e edita Medidas Provisórias (914 e 979) para interferir nas eleições de reitoria pelas comunidades, afrontando a autonomia universitária garantida na Constituição Federal. Também insensível às demandas sociais, o MEC só flexibilizou a data do Exame Nacional do Ensino Médio (Enem) quando houve determinação do Senado Federal, e a manutenção da data anteriormente definida prejudicaria sensivelmente estudantes de escolas públicas de ensino médio que também estão sem encontros presenciais por força da pandemia.

Nos parece, portanto, que mais do que cessar a expansão e democratização da oferta da educação superior pública e o crescimento do seu financiamento, a gestão pública federal ataca as condições dos mais vulneráveis e tenta recolocar barreiras a lutas históricas dos movimentos sociais. Ao caso emblemático do ENEM, soma-se a proposta do Ensino Remoto Emergencial (ERE) como ameaça à inclusão educacional dos mais pobres. Esta proposta acaba por excluir aqueles estudantes que tem dificuldade de acesso à internet, sem falar das condições para o estudo em suas casas.

O ERE está sendo colocado em debate como alternativa de manutenção de atividades acadêmicas de ensino em todos os níveis de educação, e assim se coloca também para a educação superior. ${ }^{\circ}$ O Conselho Nacional de Educação emitiu parecer sobre a organização de estudos via mecanismos virtuais no parecer CNE/CP n ${ }^{\circ}$ 05/2020, homologado parcialmente pelo MEC em 29 de maio de 2020. Abre-se a possibilidade de flexibilização de dias letivos e de carga horária, com forte recomendação de adoção de mecanismos não presenciais de educação. A medida tem gerado discussão no meio acadêmico, nos gestores de políticas públicas, movimentos sociais e sindicatos patronais e de professores, além de associações de pais e outros interessados no debate educacional, como associações científicas do campo.

A adoção massiva de tecnologias e mecanismos de educação remota coloca (ou recoloca), em nosso entendimento, uma barreira ao incipiente processo de inclusão e democratização do acesso e da permanência/sucesso na educação superior brasileira. Barreira essa que atinge de modo desigual diferentes segmentos de estudantes, e são justamente os mais vulneráveis, aqueles que historicamente precisaram lutar muito para transpor outras barreiras, agora se 
veem novamente excluídos pela incapacidade de dispor e de poder usar ferramentas virtuais de acesso à aprendizagem.

No caso particular da UFRGS, por exemplo, a universidade começou a fazer em abril as primeiras sondagens com o corpo discente para levantar as condições que os estudantes têm ou teriam para acompanhar atividades nos moldes do ERE. Primeiramente alguns cursos fizeram levantamentos isolados, e depois houve um levantamento institucional feito pela Pró-Reitoria de Graduação (PROGRAD), respondido por 46\% dos estudantes de graduação e por $57 \%$ dos alunos beneficiários da política de assistência estudantil.

Mesmo sem ser amostral, a pesquisa é a única referência institucional nesse momento. Nela se aponta que o acesso dos estudantes à Internet se dá majoritariamente via telefone ou notebook, com uso alternado de dados próprios ou redes wi-fi. Metade dos estudantes compartilha, contudo, seus equipamentos com outras pessoas da família.

A pesquisa ainda aponta uma clara divisão entre o tipo de atividade remota que conseguem acessar pela Internet, entre atividades em tempo real e atividades off-line, assistidas em tempo distinto da que estão ocorrendo. Cerca de 40\% dos estudantes informaram ter dificuldades para estudar no período da pandemia, em função da assunção de tarefas domésticas, familiares ou de trabalho, e sustentam que tem mantido quase nenhum contato com a instituição e com professores nesse período.

Entendemos que tal quadro também pode ser cotejado com pesquisa anterior feita pelo Programa de Pós-Graduação em Informática na Educação, ligado ao CINTED/UFRGS, e publicada em 2019. A pesquisa se detém no uso de dispositivos móveis e aplicativos nas experiências de aprendizagem discente na UFRGS. Os resultados, (OBSERVATÓRIO DE INOVAÇÃO PEDAGÓGICA COM TECNOLOGIA, 2021) ainda que não sejam apresentados de forma segmentada pelos níveis pesquisados -- graduação, especialização, mestrado e doutorado --, estão segmentados por áreas de conhecimento e permitem um panorama razoável para análise.

Nessa pesquisa, quase a totalidade dos estudantes (95\%) possuem algum dispositivo móvel com acesso à Internet. O que à primeira vista pode parecer um quadro extremamente favorável à disseminação irrestrita de uso de ferramentas virtuais de ensino-aprendizagem, ganha contornos diferentes à medida que se olham os pormenores da pesquisa. 
Há um peso bem grande nas respostas que demonstram incerteza quando a questão a respeito de "se o professor deveria usar mais" mecanismos, dispositivos e métodos online. Pode-se inferir que há grande desconhecimento dos estudantes sobre o que isso representaria, apesar de todos parecerem ter bastante familiaridade com internet e dispositivos móveis (e com a combinação de ambos).

Apesar dessa familiaridade dos estudantes, quando a pesquisa também apresenta o resultado à pergunta "quais motivos faz com que o estudante não queira que o professor exija mais uso de aplicativos móveis", e as três principais respostas foram:

a. limitação de conexão com a internet;

b. recursos financeiros limitados;

c. acesso limitado ou sem acesso a dispositivos móveis.

Além disso, os obstáculos indicados pelos discentes ao processo de aprendizagem via dispositivos móveis passa por várias limitações materiais (vida útil dos aparelhos, duração das baterias, limitação de velocidade da internet - nos seus planos e na UFRGS - e medo de roubo) e pedagógicas (cansaço do método virtual, dificuldade de concentração, baixa interação social na sala de aula e outros).

Há, por fim, questões sociais que não são foco da pesquisa: não podemos saber, então, como está a vida dos estudantes, especialmente durante a pandemia e a sua futura - e lenta - saída. Há que se investigar se, em casa, os discentes teriam condições de estudar e conciliar isso com trabalho e com cuidados familiares, num horizonte de tempo de adaptações que podem durar até dois anos.

Outro ponto a descoberto a respeito da realidade dos discentes é o conhecimento específico que estes possuem para uso das ferramentas. A própria pesquisa (que se limita aos dispositivos móveis) mostra alto grau de desconhecimento dos aplicativos UFRGS (menos da metade usa o Moodle Mobile) e alguns apontam a necessidade de um aplicativo de mapas dos prédios da UFRGS, o que já existe.

Se cruzarmos essas pesquisas da UFRGS com dados de outras universidades, como a própria USP, (LIMA, 2020) onde se aponta ainda grande defasagem e diferença de acesso entre seu corpo discente, vamos encontrar sentido nos dados da pesquisa TICDomicílios. Essa pesquisa anual, baseada em dados da PNAD e PNAD contínua do Instituto Brasileiro de Geografia e Estatística (IBGE), levanta as condições de acesso a Tecnologias de Informação e de Comunicação (TIC) nos domicílios brasileiros. Os dados de 
2019 (TIC DOMICÍLIOS, 2020) informam de modo inequívoco que o acesso à internet, o tipo de banda de acesso e os equipamentos disponíveis para navegar são inversamente proporcionais à classe social do domicílio, e que os principais motivos da falta de acesso são o preço dos serviços e o fato de não se saber utilizar a internet.

Fica claro, portanto, que as melhores ou piores condições de acesso a internet, redes e equipamentos confiáveis e de performance razoável para o estudo remoto são determinadas por constrangimentos materiais e econômicos.

Some-se a isso, no caso particular da UFRGS, em que a adoção da Educação a Distância (EaD), de modo estruturado, ainda é bastante tímida, ${ }^{5}$ de modo que o aproveitamento dessa expertise, ou da infraestrutura já instalada para EaD, parecem ser insuficiente em escala e escopo para dar conta de fazer chegar com qualidade a proposta de Ensino Remoto a todos cursos e estudantes.

A partir desse quadro, se pode depreender que a adoção massiva do ERE demandaria que os próprios estudantes precisam dispor de seus equipamentos e conexões, de um ponto de vista material, e também de seu tempo e espaços pessoais para estudar e acompanhar uma atividade de ensino que venha a ser conduzida remotamente. Nesse ponto, volta-se às condições levantadas anteriormente de insuficiência e/ou incapacidade de arcar com os custos econômicos dessa estrutura própria.

Há, por fim, mas de modo não menos importante, salientar os efeitos da pandemia no agravamento das condições da saúde mental no meio acadêmico, que já eram objeto de preocupação por parte da própria universidade (ARENAS; ANDRADE, 2019) no ambiente acadêmico. Pesquisadores da própria universidade publicaram recentemente artigo científico sobre o tema. (UNIVERSIDADE FEDERAL DO RIO GRANDE DO SUL, 2020)

Contudo, a Universidade fecha os olhos a toda esta realidade e com o intuito de "não perder tempo" e retomar as aulas, aceitando o que se chama de "nova normalidade", reduzindo o ensino à absorção de conteúdo. Infelizmente, portanto, parece que este tempo pandêmico não tem provocado mudanças em nós, individualmente, mas também nas instituições que poderiam rever seu próprio sentido. Se confirmadas as estratégias de retomada para não se "perder tempo", corremos o risco de "perder gente" pelo caminho, justamente aquelas que tinham ficado historicamente
(5) As páginas das Pró-Reitoria de Graduação e da Secretaria de Educação à Distância (SEAD) da UFRGS não publicam qual percentual de disciplinas e carga horária dos cursos de graduação presenciais é ofertado na modalidade EaD. Segundo o painel de dados da UFRGS, atualmente são ofertados 97

cursos de graduação, 84 cursos de doutorado, 74 de mestrado acadêmico, 8 cursos de mestrado profissional e 116 cursos em andamento. Pela página da SEAD, são ofertados totalmente na modalidade à distância cinco cursos de graduação (com

matrícula de 658 alunos dos 32.491 alunos), todos edições especiais e que não compõem a grade de oferta permanente da universidade. 
impedidas de acessar a educação superior pública, e que tímida e vagarosamente vinham conquistando esse direito.

\section{Considerações finais}

Neste artigo procuramos avaliar as soluções que estão sendo construídas para a educação em tempos de pandemia, a partir da perspectiva de que tal condição deverá manter longe da escola, da universidade e dos processos de aprendizagem aqueles estratos populacionais que já são marcados por outras desigualdades econômicas, sociais e culturais. Não nos detivemos na educação básica e suas particularidades, em que nos parece ainda mais importante a relação presencial, como em processos de alfabetização ou educação de jovens e adultos, por exemplo.

Trouxemos o exemplo do ensino superior, no qual a exclusão educacional parece atingir seu grau máximo no Brasil, e onde historicamente se pode visualizar a nefasta interdição ao saber que é imposta aos segmentos mais vulneráveis, empobrecidos e discriminados em nossa sociedade. Pessoas pobres, pretas, indígenas e com deficiência, depois de muita luta foram conquistando políticas afirmativas de acesso e permanência no ensino superior público, condição agora seriamente ameaçada pelas propostas de ensino remoto, e que já vinham sendo corroídas pelo desfinanciamento das universidades públicas e das políticas específicas como o PNAES.

Esse ataque se agrava de forma perversa, com a recente crise sanitária trazida pela pandemia da COVID-19. Os dilemas entre cuidados pessoais e a necessidade premente de seguir trabalhando para dar conta das necessidades materiais, não só tomam o tempo, mas também a saúde mental das famílias cujos filhos passaram a frequentar a universidade pública na última década. A péssima gestão pública da crise recoloca a fome e as doenças no repertório de preocupações dos mais frágeis, cenário em que a educação superior e o sonho da mobilidade social e das melhores condições de vida vão ficando pelo caminho, outra vez, para as mesmas pessoas.

Continuaremos na impossibilidade de enterrar nossos mortos, e se não aprendermos com esta experiência dolorosa, perderemos muitos jovens que duramente, por muito tempo, lutaram para estarem na Universidade. Nosso texto é também um manifesto de Antígona: queremos não só direito ao luto, mas também direito à educação e à vida digna. 


\title{
Higher education: the Antígonas of our pandemic times and the social inequalities worsening
}

\begin{abstract}
Brazilian historical social inequalities have been highlighted in the present COVID-19 pandemic. As consequences of colonization processes that shaped our society, such inequalities make possible to remain present amongst us, without proper confrontation, the racism, gender violence and the exploitation of work. All of these issues, in a time of profound health weakness, show us that those who suffer the most remain the poorest. COVID-19 shows us the most violent face of this inequality. The field of Education is also affected by this scenario. Once presential classes have been suspended, Emergency Remote Teaching (ERT) is shown as the best solution, but the case of Federal University of Rio Grande do Sul, here described, allows us to stand that this solution may probably deepen the mentioned inequalities.
\end{abstract}

Keywords: Colonization. Pandemic. Emergency Remote Teaching. Social Inequalities.

\section{La educación superior: las Antígonas de nuestro tiempo pandémico y el agravamiento de las desigualdades sociales}

\begin{abstract}
Resumen: La pandemia que estamos experimentando ha agravado las desigualdades sociales históricas en Brasil. Las desigualdades que presenciamos son consecuencias de los procesos de colonización experimentados hasta el presente, una vez que no podemos enfrentar el racismo, la violencia de género y la explotación del trabajo. Todos estos problemas, en un momento de profunda debilidad de la salud, nos muestran que quienes más sufren en crisis como estas, siguen siendo los más pobres. La COVID-19 nos muestra la cara más violenta de esta desigualdad. El campo de la educación también se ve afectado por este escenario. Con la suspensión de las clases presenciales, se buscó compensar la enseñanza a través de propuestas de actividades remotas (ERE), pero nuestras reflexiones preliminares permiten sostener que tales estrategias pueden agravar aún más las desigualdades referidas. Para ejemplificar, el presente artículo discute el caso de la Universidad de Rio Grande do Sul, y los riesgos implicados en este proceso.
\end{abstract}

Palabras clave: Colonización. Pandemia. Enseñanza Remota de Emergencia. Desigualdades socio educacionales

\section{Referências}

AMARAL, N. C. A educação superior brasileira: dilemas, desafios e comparações com os países do OCDE e BRICS. Revista Brasileira de Educação, Rio de Janeiro, v. 21, n. 66, jul./set. 2016. Disponível em: http://www.scielo.br/scielo.php?script = sci_abstract\&pid $=$ S1413$24782016000300717 \mathcal{E} 1 \mathrm{ng}=$ enE $\mathrm{nrm}=$ iso\&tlng = pt. Acesso em: 29 abr. 2019.

ANJOS, J. C. G. dos. A religiosidade afro-brasileira e a política de reserva de vagas na Universidade Federal do Rio Grande do Sul. In: 
SANTOS, J. T. (org.). Cotas nas universidades: análises dos processos de decisão. Salvador: CEAO, 2012. p. 183-207.

ANDIFES. V Pesquisa nacional de perfil socioeconômico e cultural dos (as) graduandos (as) das IFES - 2018. Brasília, DF: Andifes: FONAPRACE, 2019.

ARENAS, D. L.; ANDRADE, A. C. de. Como anda a saúde mental na Universidade? Jornal da Universidade (JU), Porto Alegre, 5 set. 2019. Disponível em: https://www.ufrgs.br/jornal/como-anda-a-saudemental-na-universidade/. Acesso em: 30 jun. 2020.

ARENAS, D. L.; ANDRADE, A. C. de. PEC 241/55: a morte do PNE (2014-2024) e o poder de diminuição dos recursos educacionais. RBPAE, Porto Alegre, v. 32, n. 3, p. 653-673, set./dez. 2018. Disponível em: https://seer.ufrgs.br/rbpae/article/view/70262. Acesso em: 29 abr. 2019.

BARBOSA E SILVA. L. Racismo institucional e as oportunidades acadêmicas nas IFES. Revista Brasileira de Ensino Superior, Passo Fundo, v. 3, n. 3, p. 80-99, 2017. Disponível em: https://seer.imed.edu.br/ index.php/REBES/article/view/2028. Acesso: 14 ago. 2018.

BRASIL. Ministério da Educação. Análise sobre a expansão das universidades federais 2003 a 2012. Brasília, DF: MEC, 2012.

BRASIL. Decreto n. 7.234, de 19 de julho de 2010. Dispõe sobre o Programa Nacional de Assistência Estudantil - PNAES. Diário Oficial República Federativa do Brasil. Brasília: DF, 20 jul. 2010. Disponível em: http://www.planalto.gov.br/ccivil_03/_ato2007-2010/2010/decreto/ d7234.htm. Acesso: 14 set. 2020.

BRASIL. Lei n. 12.711, de 29 de agosto de 2012. Dispõe sobre o ingresso nas universidades federais e nas instituições federais de ensino técnico de nível médio e dá outras providências. Diário Oficial República Federativa do Brasil. Brasília: DF, 30 ago. 2012. Disponível em: http:// www.planalto.gov.br/ccivil_03/_ato2011-2014/2012/lei/112711.htm. Acesso: 11 set. 2020

BRASIL. Parecer Conselho Nacional de Educação, Conselho Pleno, 05/2020. Diário Oficial República Federativa do Brasil. Brasília: DF, 01 jun. 2020. Disponível em: http://portal.mec.gov.br/index. php?option $=$ com_docman\&view $=$ downloadEalias $=14511-$ pcp00520Ecategory_slud $=$ marco-2020-pdfEItemid $=30192$. Acesso em: 11 set. 2020 .

CENTRO DE ESTUDOS E DEBATES ESTRATÉGICOS DA CÂMARA DOS DEPUTADOS. Financiamento da educação superior no Brasil: impasses e perspectivas [recurso eletrônico]. Brasília: Câmara dos deputados, edições Câmara, 2018. Disponível em: https://www2.camara.leg.br/acamara/estruturaadm/altosestudos/pdf/financiamento-da-educacaosuperior-no-brasil-impasses-e-perspectivas. Acesso em: 28 abr. 2019. 
COMITÊ GESTOR DA INTERNET NO BRASIL. Pesquisa TIC domicílios 2019. Brasília, DF: CETIC, 2019.Disponível em: https://cetic.br/pt/ pesquisa/domicilios/. Acesso em: 14 set. 2020.

FERNANDES, F. Universidade e desenvolvimento. In: FERNANDES, F. Universidade brasileira: reforma ou revolução? São Paulo: Alfa-Ômega, 1975, p. 91-123.

KILOMBA, G. Memórias da plantação: episódios de racismo cotidiano. [Rio de Janeiro]: Cobogó, 2019.

LIMA, A. Ensino remoto emergencial deve levar em conta acesso de alunos à internet. Jornal da USP, São Paulo, 03 jun. 2020. Disponível em: https://jornal.usp.br/atualidades/ensino-remoto-emergencialdeve-levar-em-conta-acesso-de-alunos-a-internet/. Acesso em: 30 jun. 2020.

PLATÃO. A República. Tradução Pietro Nassetti. São Paulo: Martin Claret, 2002, 319p.

OBSERVATÓRIO DE INOVAÇÃO PEDAGÓGICA COM TECNOLOGIA. Porto Alegre: UFRGS, c2021. Disponível em: https://www.ufrgs.br/ observatorio-inov-pedag/publicacoes/. Acesso em: 25 jun. 2020.

QUIJANO. A. Colonialidade do poder, eurocentrismo e América Latina. Buenos Aires: Biblioteca da CLACSO, 2005.

REUTERS, L. P. Negros sem escolaridade têm 4 vezes mais chances de morrer por Covid-19 no Brasil, mostra estudo. Portal G1, [Rio de Janeiro, RJ]: Grupo globo, 2020. Disponível em: https://g1.globo.com/ bemestar/coronavirus/noticia/2020/05/27/negros-sem-escolaridadetem-4-vezes-mais-chances-de-morrer-por-covid-19-no-brasil-mostraestudo.ghtml. Acesso em: 12 jun. 2020.

SANTOS, B. de S.; MENESES, M. P. Epistemologias do sul. São Paulo: Cortez, 2010.

SÓFOCLES. Antígona. Tradução J. B. de Mello e Souza. 2005. (Clássicos Jackson, v. XXII). Disponível em: https://direitorio.fgv.br/sites/ direitorio.fgv.br/files/antigona.pdf. Acesso em: 1 Out. 2018.

TURTELLI, C. Weintraub: Universidades com aulas serão premiadas. Educação. Terra. São Paulo, 2020. Disponível em: https://www.terra. com.br/noticias/educacao/weintraub-universidades-com-aulas-serao-pr emiadas, fa07cbf55cbbd6b714a360cfa4aec8c0p8725o04.htm1. Acesso em: 11 set. 2020.

TIC DOMICÍLIOS. São Paulo: CETIC, 2020. Disponível em: https:// www.cetic.br/pesquisa/domicilios/. Acesso em: 30 jun. 2020

UNIVERSIDADE FEDERAL DO ESPÍRITO SANTO. Andifes divulga números sobre a atuação das universidades no combate à COVID-19. Vitoria: UFES, 2020. Disponível em: https://www.cnnbrasil.com.br/ politica/2020/03/27/governo-lanca-campanha-brasil-nao-pode-pararcontra-medidas-de-isolamento. Acesso em: 20 jun. 2020. 
UNIVERSIDADE FEDERAL DO RIO GRANDE DO SUL. Pesquisadores da UFRGS alertam para impactos na saúde mental em decorrência de uma pandemia. Porto Alegre: UFRGS, 2020. Disponível em: http:// www.ufrgs.br/ufrgs/noticias/pesquisadores-da-ufrgs-alertam-paraimpactos-na-saude-mental-em-decorrencia-uma-pandemia. Acesso em: 30 jun. 2020.

ZEA, L. Discurso desde a marginalização e a barbárie: a filosofia latinoamericana como filosofia pura e simplesmente. Rio de Janeiro, RJ: GARAMOND, 2005.

ZIMMERMAN, R. América Latina: o não ser. Petrópolis: VOZES, 1987.

Submetido em 19/07/2020.

Aceito em 31/10/2020. 
